https://doi.org/10.15407/ujpe65.6.542

I.V. PLYUSHCHAY, ${ }^{1}$ T.V. GORKAVENKO, ${ }^{1}$ O.I. PLYUSHCHAY ${ }^{2}$

1 Taras Shevchenko National University of Kyiv

(64/13, Volodymyrs'ka Str., Kyiv 01601, Ukraine; e-mail: inna.plyushchay@gmail.com, tvgorka@gmail.com)

2 G.V. Kurdyumov Institute for Metal Physics, National Academy of Sciences of Ukraine (36, Academician Vernadsky Blvd., Kyiv 03142, Ukraine)

\title{
BORON IMPURITY EFFECT ON THE STRUCTURAL, ELASTIC, AND ELECTRONIC PROPERTIES OF TITANIUM CARBIDE ${ }^{1}$
}

\begin{abstract}
Atomic, structural, and elastic properties of titanium carbide with the boron impurity have been studied in the framework of the density functional theory in the general gradient approximation, by using the software ABINIT. The calculations of the total energy of a TiC supercell with boron impurity atoms showed that the latter do not tend to form clusters in titanium carbide. The equilibrium distances between the adjacent planes of titanium atoms were found to increase in the presence of the boron impurity. The electronic spectra of TiC supercells with various numbers and positions of boron impurity atoms are analyzed. The presence of boron impurity atoms is found to result in the appearance of a subband of their electron states, which is located between the local electronic spectra of the $2 s$ and $2 p$ carbon states by about 0.24 Hartree below the Fermi level. The coordination positions of boron impurity atoms affect only the shape and half-width of their electronic subband. An insignificant increase in the electron density of states just below the Fermi level also takes place. The bulk modulus of a titanium carbide supercell with boron impurity atoms is calculated and analyzed.
\end{abstract}

Ke ywords: titanium carbide, boron impurity, atomic structure, elastic properties, electronic structure.

\section{Introduction}

The issues associated with the creation and fabrication of highly durable materials are very important for the further development of engineering and advanced technologies. Therefore, the elaboration of ceramic-matrix composites has a particular importance, since those composites are characterized by a higher resistance to the destruction in comparison with a monolithic ceramics. Solid-alloy composites of transition metals are good candidates for their practical application under extreme conditions be-

(c) I.V. PLYUSHCHAY, T.V. GORKAVENKO, O.I. PLYUSHCHAY, 2020 cause of the excellent combination of their mechanical and electrical properties, as well as their high corrosion and oxidation resistance at high temperatures. In particular, materials on the basis of titanium boride and titanium carbide possess remarkable physical and mechanical characteristics such as the hardness, corrosion resistance, Young's modulus, and high melting point. In addition, recent studies have demonstrated that the metal ceramics on the basis of $\mathrm{TiC}_{-} \mathrm{TiB}_{2}$ composite have higher hardness and chemical resistance at high temperatures, being considered a good

1 The paper was presented at XXIVth Galyna Puchkovska International School-Seminar "Spectroscopy of Molecules and Crystals" (August 25-30, 2019, Odesa, Ukraine).

ISSN 2071-0194. Ukr. J. Phys. 2020. Vol. 65, No. 6 
alternative to the wear-resistant application of metal ceramics on the basis of tungsten carbide (WC) [1-3].

One of the most efficient ways to produce TiC$\mathrm{TiB}_{2}$ heteroceramics is the reactive hot pressing of a $\mathrm{TiC}-\mathrm{B}_{4} \mathrm{C}$ mixture. Therefore, there arises a challenging problem consisting in discovering the atomic mechanisms giving rise to the nucleation of titanium diboride $\left(\mathrm{TiB}_{2}\right)$, as well as in a theoretical study of the electronic and elastic properties of $\mathrm{TiC}$ with the boron impurity.

\section{Calculation Results and Their Discussion}

This work is devoted to the $a b$ initio study of the influence of the boron impurity on the structural, mechanical, and electronic properties of titanium carbide. The theoretical calculations are performed in the framework of the density functional method [4] in the generalized gradient approximation [5] and using the software ABINIT [6].

\subsection{Atomic structure}

Titanium carbide is known to possess a NaCl-type structure. The latter can be represented as two hcc lattices of titanium and carbon atoms that are shifted with respect to each other by the half-lattice period along any of the $\langle 100\rangle$ edges. Accordingly, in the (111)-type planes, there are alternating layers filled with only titanium or carbon atoms that are arranged according to the structure of close-packed spheres. In order to elucidate the influence of the boron impurity on the titanium carbide properties, a $\mathrm{TiC}$ supercell with 24 atoms was constructed. Namely, it contained three (111)-type planes of titanium atoms (close sphere packings of types A, B, and C) with 4 atoms in each plane; and the same planes for carbon atoms. Hence, the initial supercell can be described as Ti12C12.

Then boron atoms were arranged in this supercell either at the carbon atom substitution positions or at the interstitial positions corresponding to the positions of boron atoms in $\mathrm{TiB}_{2}$. Titanium boride also consists of layers composed of titanium atoms with the structure of close-packed spheres (e.g., of type A) which alternate with graphite-like layers of boron atoms (positions $\mathrm{B}$ and $\mathrm{C}$ ). The distance between the layers of close-packed titanium atoms in $\mathrm{TiB}_{2}$ is larger than in $\mathrm{TiC}$ by about $28 \%$. After the introduction of boron impurity atoms into the Ti12C12 supercell and

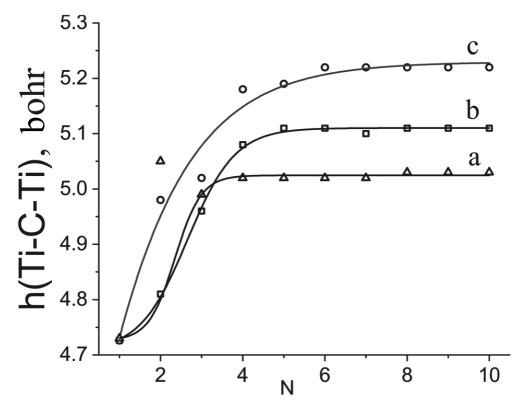

Fig. 1. Changes of the distance between the adjacent planes of close-packed Ti atoms in a Ti12C12 supercell: $(a)$ two boron atoms replace two carbon atoms, $(b)$ three boron atoms replace three carbon atoms, and $(c)$ two boron atoms replace two carbon atoms and the third boron atom occupies an interstitial position

in order to relax internal stresses, a numerical annealing procedure of the atomic positions was carried out in accordance with the forces calculated from the first principles.

Figure 1 illustrates a change of the distance between the adjacent planes of close-packed layers of titanium atoms in the $\mathrm{TiC}$ cell in the course of numerical annealing ( $N$ is the annealing step number), when boron atoms are inserted into the layer of carbon atoms: (a) two boron atoms replace two carbon atoms; $(b)$ three boron atoms replace three carbon atoms; and $(c)$ two boron atoms replace two carbon atoms, and the third boron atom is at the immersion position (which corresponds to the graphite-like layer of boron atoms in $\mathrm{TiB}_{2}$ ). One can see that ten steps of the numerical annealing are enough to achieve the equilibrium distance between the corresponding atomic layers.

In the case where two boron impurity atoms replace two carbon atoms, the distance between the adjacent layers of close-packed Ti atoms increases by about $6 \%$ (curve $a$ in Fig. 1). Three boron impurity atoms at the substitution positions increase the corresponding interplanar distance by approximately $8 \%$ (curve $b$ in Fig. 1). Finally, if two boron impurity atoms are at the substitution positions, and if the third one is at the interstitial position, the distance between the adjacent layers of close-packed Ti atoms increases by $10.5 \%$ (curve $c$ in Fig. 1). This result is quite expected, because the covalent radius of a boron atom is larger than that of a carbon atom.

Hence, the results of calculations from the first principles allow an assumption to be made about the 


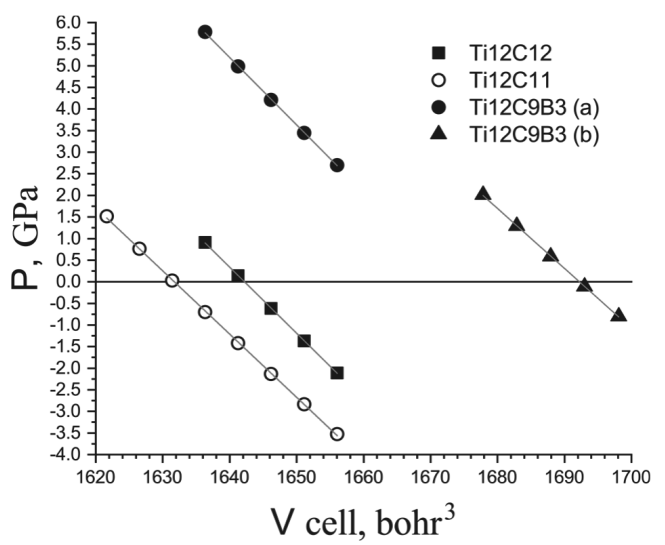

Fig. 2. Pressure changes at the uniform compression/extension of Ti12C12, Ti12C11, and Ti12C9B3 [before annealing $(a)$, after annealing $(b)]$ supercells

mechanism of $\mathrm{TiB}_{2}$ formation during the hot pressing of the $\mathrm{TiC}-\mathrm{B}_{4} \mathrm{C}$ system. Boron atoms, which can be captured at carbon vacancies in substoichiometric titanium carbide $\mathrm{TiC}_{X}$ during the hot pressing of $\mathrm{TiC}$ $\mathrm{TiB}_{2}$ heteroceramics, increase the distance between the (111)-type planes in $\mathrm{TiC}$ and thus enhance the probability for additional boron atoms to be included into the $\mathrm{TiC}$ lattice.

We also studied the behavior of boron impurity atoms from the viewpoint of their tendency to form clusters in titanium carbide. For this purpose, the changes in the total energy of the Ti12C12 supercell for various numbers and positions of boron impurity atoms were analyzed. The impurity atoms were arranged so that the numbers of adjacent impurity atoms in the first coordination sphere of non-metallic atoms should be different. The corresponding additional analysis, as well as the results of works $[7,8]$, testifies that the boron impurity atoms in titanium carbide do not tend to form clusters.

\subsection{Elastic properties}

In order to determine the influence of the boron impurity on the elastic characteristics of titanium carbide, the calculations of the electron subsystems of Ti12C12 supercells with various numbers and positions of defects under isotropic compression and extension conditions were carried out. As one can see from Fig. 2, the corresponding pressure calculated from the first principles changes linearly at that, which makes it possible to determine the bulk modulus according to the formula $B=-V(d P / d V)$.
It is known [9] that, as a rule, titanium carbide exists in the substoichiometric form $\mathrm{TiC}_{X}$ with a certain concentration of carbon vacancies. In one of the pioneering works devoted to the study of the mechanical properties of titanium carbide, the substoichiometric compound $\mathrm{TiC}_{0.91}$ was considered [10]. It is the results obtained for substoichiometric $\mathrm{TiC}_{X}$ that should be compared with the experimental ones. Therefore, we firstly studied the behavior of the Ti12C12 and Ti12C11 supercells corresponding to $\mathrm{TiC}$ and substoichiometric $\mathrm{TiC}_{0.92}$, respectively [11]. By linearly approximating the pressure dependences on the supercell volume $V$ (Fig. 2), the following values of the bulk modulus $B$ were obtained: $B=251 \pm 1$ GPafor the Ti12C12 supercell and $B=238 \pm 1$ GPafor the Ti12C11 one. The results obtained are in good agreement with the results of experimental measurements, from the pioneering experimental study of the elastic properties of titanium carbide $\mathrm{TiC}_{0.91}(B=242 \mathrm{GPa}[10])$ to electronic databases for the properties of ceramic materials. In the latter case, the corresponding elastic moduli of titanium carbide fall within an interval of 234-241 GPa.

There is an opinion [12] that, when metal-ceramic composites of the $\mathrm{TiC}-\mathrm{TiB}_{2}$ system are fabricated by the hot pressing of a $\mathrm{TiC}_{-} \mathrm{B}_{4} \mathrm{C}$ mixture, the boron atoms diffuse in both the vacancy positions and the substitution positions of carbon atoms. Therefore, we performed an $a b$ initio simulation of the state of the Ti12C12 supercell with various numbers and positions of boron impurity atoms. As an example, Fig. 2 demonstrates the pressure dependence on the volume of the Ti12C9B3 supercell in which all three boron impurity atoms are at the substitution positions of carbon atoms in the same plane. As one can see (curve Ti12C9B3( $a)$ ), the substitution of carbon atoms by boron ones with a larger covalent radius leads to a substantial pressure growth before the annealing. The linear approximation of the corresponding curve gives a value of $261 \pm 2 \mathrm{GPa}$ for the bulk modulus. However, this result is not reliable, because the stresses in such an unannealed cell are not isotropic.

After the procedure of numerical annealing of the atomic positions and the supercell size, a quite expected increase in the supercell specific volume was obtained (curve Ti12C9B3(b) in Fig. 2). The corresponding value of the bulk modulus was found to 
equal $240 \pm 2 \mathrm{GPa}$. In effect, the calculated value coincides with its counterpart for the substoichiometric titanium carbide $\mathrm{TiC}_{0.92}$ (as was marked above, the latter value correlates well with the values obtained for the bulk modulus experimentally in various literature sources). This fact allows us to suggest that the boron impurity has an insignificant effect on the elasticity parameters of titanium carbide, at least in the examined interval of impurity atom concentrations.

\subsection{Electronic structure}

In this work, in order to analyze the influence of boron impurity atoms on the electronic properties of titanium carbide, we calculated the total energies and plotted the spectra of the electron density of states for Ti12C12 supercells with various numbers and positions of boron impurity atoms.

Firstly, let us analyze the electronic structure of titanium carbide. The energy dependence of the electron density of states in titanium carbide is depicted in Fig. 3. The figure demonstrates $(a)$ the total spectrum of titanium carbide and the spectra of its $(b) 3 d \mathrm{Ti}$ and $(c) 2 s \mathrm{C}$ and $2 p \mathrm{C}$ components, which are shifted along the $y$-axis for convenience. The Fermi level is indicated by a vertical line. According to the results of our calculations, as one can see from Fig. 3, the electron states near the Fermi level almost entirely consist of the $3 d$ states of titanium atoms and the $2 p$ states of carbon ones.

It is known that the binding in titanium carbide simultaneously possesses the metallic, ionic, and covalent features, which results in a very interesting combination of the physical and chemical properties of this compound. The results of our calculations confirmed the presence of all three contributions to the binding. The non-zero electron density of states at the Fermi level, which is created from approximately identical contributions of the $3 d$ Ti states and the $2 p \mathrm{C}$ states, is responsible for the metallic contribution to the binding. The ionic character of the binding is confirmed by a substantial electron density transfer (more than 1 electron per atom) ${ }^{2}$ from Ti to C. However, the spectra presented in Fig. 3 testify that the role of the dominant factor governing the behavior of electron peaks near the Fermi level is played by a strong covalent bond among the hybridized Ti3d-C $2 p$

\footnotetext{
2 It was impossible to evaluate the amount of charge transfer more accurately in the framework of our calculation method.
}

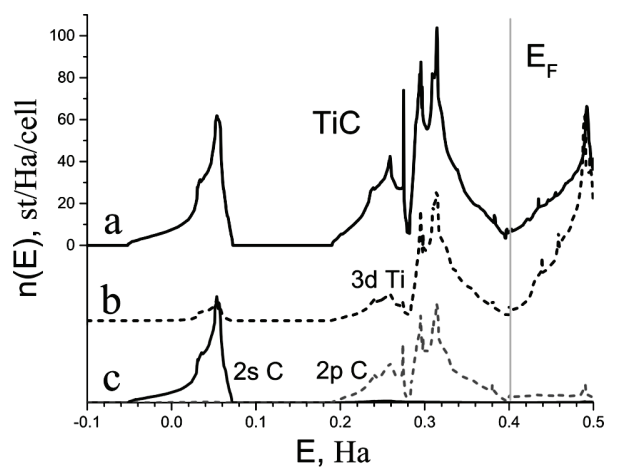

Fig. 3. Electron densities of states: (a) titanium carbide, (b) local $3 d$ Ti spectrum, (c) local $2 s \mathrm{C}$ and $2 p \mathrm{C}$ spectra

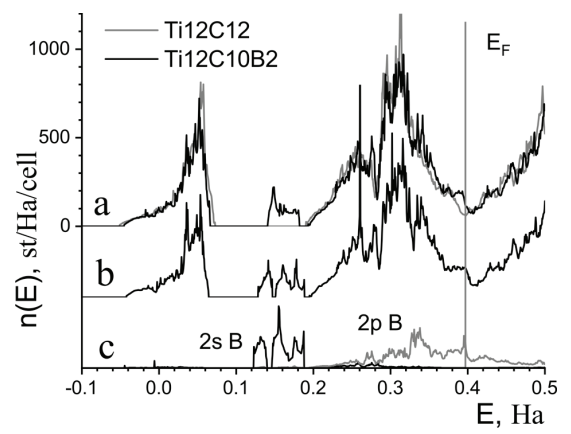

Fig. 4. Electron densities of states: (a) Ti12C10B2 (black) and Ti12C12 (gray) supercells, (b) Ti12C9B3 supercell, (c) local $2 s$ B and $2 p$ B spectra for Ti12C9B3 supercell

orbitals. It is this bond that is responsible for the high stability, strength, and hardness of titanium carbide.

By introducing boron impurity atoms into the titanium carbide supercell, as well as by changing the number and positions of adjacent impurity atoms in the first coordination sphere of non-metallic atoms, we calculated and analyzed the corresponding variations in the electronic structure. A detailed description of all possible variants of the positions of impurity atoms and their coordination environment can be found in works $[7,8]$.

As an example, curve $a$ in Fig. 4 demonstrates the energy dependence of the electron density of states for a Ti12C9B2 supercell in which two boron impurity atoms replace carbon atoms. In order to make the analysis convenient, the same figure exhibits the energy dependence of the electron density of states for a Ti12C12 supercell (in gray). Owing to the presence of boron impurity atoms, there appears an impurity subband of the boron electron states between the local electron spectra of the $2 s$ and $2 p$ car- 
bon states at approximately 0.24 Hartree below the Fermi level. One can also observe an insignificant increase in the electron density of states just below the Fermi level.

Various coordination arrangements of boron impurity atoms affect only the shape and half-width of the subband of their electron density of states. In particular, curve $b$ in Fig. 4 illustrates the electronic spectrum of a Ti12C9V3 supercell in which all three boron atoms occupy the substitution positions of carbon atoms in such a way that the impurity atoms should be located as close to one another as possible. Accordingly, the aforementioned impurity subband has the largest width and a certain internal structure. An analysis of the local partial spectra of boron impurity atoms (curve $c$ in Fig. 4) revealed that the impurity subband is formed by the $2 s$ states of boron atoms, and the increase in the electron density of states just below the Fermi level is induced by their $2 p$ states. As a whole, the local spectrum of a boron atom substituting a carbon atom is similar to the local spectrum of a carbon atom in titanium carbide (curve $c$ in Fig. 3), but it is shifted toward higher energies. This behavior can be completely understood, because the charge of a boron atom is smaller.

\section{Conclusions}

In the course of a thorough study dealing with the influence of the boron impurity on the atomic, elastic, and electronic properties of titanium carbide, it is found that the presence of boron impurity atoms increases the distance between the adjacent planes of titanium atoms. The distance growth is larger, if at least one boron impurity atom occupies an interstitial position. It is also established that boron impurity atoms do not tend to form clusters in titanium carbide.

The calculations of the bulk modulus carried out for titanium carbide with boron impurity atoms from the first principles showed that the boron impurity atoms in the examined concentration interval have an insignificant effect on the elastic properties of titanium carbide.

The electronic spectra of titanium carbide cells with various numbers and positions of boron impurity atoms are analyzed. It is found that the presence of boron impurity atoms results in the appearance of an impurity subband of the boron electron states between the local electron spectra of $2 s$ and $2 p$ carbon states at approximately 0.24 Hartree below the Fermi level. Besides that, an insignificant increase in the density of electron states just below the Fermi level takes place. The shape and the half-width of the impurity subband depend on the number and the coordination arrangement of boron impurity atoms.

1. The Physics and Chemistry of Carbides, Nitrides and Borides. Edited by R. Freer (Springer, 1989).

2. C. Cui, B. Hu, L. Zhao, S. Liu. Titanium alloy production technology, market prospects and industry development. Mater. Design 32, 1684 (2011).

3. D. Vallauri, I.C. Adrian, A. Chrysanthou. TiC-TiB 2 composites: A review of phase relationships, processing and properties. J. Eur. Ceram. Soc. 28, 1697 (2008).

4. X. Gonzea, B. Amadond, P.-M. Anglade et al. ABINIT: First-principles approach to material and nanosystem properties. Comput. Phys. Com. 180, 2582 (2009).

5. J.P. Perdew, K. Burke, M. Ernzerhof. Generalized gradient approximation made simple. Phys. Rev. Lett. 77, 3865 (1996).

6. ABINIT [http://www.abinit.org].

7. T.V. Gorkavenko, I.V. Plyushchay, O.I. Plyushchay. Ab initio modeling of boron impurities influence on electronic structure of titanium carbide. J. Nano-Electron. Phys. 10, 06018 (2018).

8. I.V. Plyushchay, T.V. Gorkavenko, O.I. Plyushchay. Ab initio modeling of boron impurities influence on the electronic and atomic structure of titanium carbide. J. NanoElectron. Phys. 11, 04034 (2019).

9. H.W. Hugosson, P. Korzhavyi, U. Jansson et al. Phase stabilities and structural relaxations in substoichiometric $\mathrm{TiC}_{1-x}$. Phys. Rev. B 63, 165116 (2001).

10. R. Chang, L.J. Graham. Low-temperature elastic properties of $\mathrm{ZrC}$ and TiC. J. Appl. Phys. 37, 3778 (1966).

11. I.V. Plyushchay, T.L. Tsaregradska, O.I. Plyushchay. Ab initio modelling of electronic structure and mechanical properties of substoichiometric $\mathrm{TiC}_{x}$. Metallofiz. Noveish. Tekhnol. 40, 1113 (2018) (in Russian).

12. O. Popov, V. Vishnyakov, S. Chornobuk et al. Mechanisms of $\mathrm{TiB}_{2}$ and graphite nucleation during $\mathrm{TiC}-\mathrm{B}_{4} \mathrm{C}$ high temperature interaction. Ceram. Internat. 45, 16740 (2019).

Received 22.10.19.

Translated from Ukrainian by O.I. Voitenko

I.В. Плющай, Т.В. Горкавенко, О.І. Плющай

ВПЛИВ БОРУ НА СТРУКТУРНІ, ПРУЖНІ ТА ЕЛЕКТРОННІ ВЛАСТИВОСТІ КАРБІДУ ТИТАНУ

Р е з ю м е

Методом функціонала густини в узагальненому градієнтному наближенні за допомогою пакета програм ABINIT про- 
ведено дослідження структурних, пружних та електронних властивостей карбіду титану за наявності домішок бору. В результаті розрахунків повної енергії надкомірки ТіС 3 домішками бору було показано, що атоми бору не виявляють схильності до кластеризації. Встановлено, що відбувається збільшення відстані між сусідніми площинами атомів титану за рахунок присутності домішкових атомів бору. Виконано аналіз електронних спектрів вибраної надкомірки 3 різною кількістю та при різних положеннях домішок. Встановлено, що завдяки наявності домішкових атомів бо- ру формується домішковий субпік електронних станів бору приблизно на 0,24 Хартрі нижче за рівень Фермі між локальними електронними спектрами $2 \mathrm{~s}$ та $2 \mathrm{p}$ станів вуглецю. Різне координаційне розташування домішкових атомів бору впливає тільки на форму та напівширину домішкової підзони електронних станів атомів бору. Також спостерігається незначне зростання густини електронних станів безпосередньо під рівнем Фермі. Обчислені та проаналізовані значення модуля всебічного стиснення надкомірки карбіду титану із домішковими атомами бору. 